\title{
Terpenes from Forests and Human Health
}

\author{
Kyoung Sang Cho ${ }^{1,2}$, Young-ran Lim ${ }^{1}$, Kyungho Lee ${ }^{1,2}$, Jaeseok Lee ${ }^{1,2}$, Jang Ho Lee ${ }^{1}$ and Im-Soon Lee ${ }^{1,2}$ \\ ${ }^{1}$ Department of Biological Sciences, Konkuk University, Seoul, Korea \\ ${ }^{2}$ Research Center for Coupled Human and Natural Systems for Ecowelfare, Konkuk University, Seoul, Korea
}

(Received February 6, 2017; Revised February 14, 2017; Accepted February 16, 2017)

\begin{abstract}
Forest bathing has beneficial effects on human health via showering of forest aerosols as well as physical relaxation. Terpenes that consist of multiple isoprene units are the largest class of organic compounds produced by various plants, and one of the major components of forest aerosols. Traditionally, terpene-containing plant oil has been used to treat various diseases without knowing the exact functions or the mechanisms of action of the individual bioactive compounds. This review categorizes various terpenes easily obtained from forests according to their anti-inflammatory, anti-tumorigenic, or neuroprotective activities. Moreover, potential action mechanisms of the individual terpenes and their effects on such processes, which are described in various in vivo and in vitro systems, are discussed. In conclusion, the studies that show the biological effectiveness of terpenes support the benefits of forest bathing and propose a potential use of terpenes as chemotherapeutic agents for treating various human diseases.
\end{abstract}

Key words: Cancer, Forest therapy, Health, Immune function, Neuronal health, Terpene

\section{INTRODUCTION}

Exposure to natural environment is beneficial to human health (1). Among environmental exposures, the effects of forest have been emphasized in many studies (2). Recently, it has been shown that a short trip to forest environments has therapeutic effects in children with asthma and atopic dermatitis (3). Based on these studies, healthcare programs to use forest have been developed in several countries $(2,4,5)$. For example, in the United States, "forest recreation" became recognized as the most valuable use of forest in the 1960s in light of social welfare (4). In Germany, a complementary and alternative medicine practice called "Kneipp therapy" is

Correspondence to: Im-Soon Lee, Department of Biological Sciences, Konkuk University, 120 Neungdong-ro, Gwangjin-gu, Seoul 05029, Korea

E-mail: islee@konkuk.ac.kr

The list of abbreviations: $B C P, \beta$-caryophyllene; GPP, geranyl pyrophosphate; DMAPP, dimethylallyl pyrophosphate; IPP, isopentenyl pyrophosphate; MAPK, mitogen-activated protein kinase; NF-KB, nuclear factor kappa $\mathrm{B}$; IL, interleukin; TNF- $\alpha$, tumor necrosis factor- $\alpha$; NO, nitric oxide; LPS, lipopolysaccharide; MMP, matrix metalloproteinases; AD, Alzheimer's disease; PD, Parkinson's disease.

This is an Open-Access article distributed under the terms of the Creative Commons Attribution Non-Commercial License (http:// creativecommons.org/licenses/by-nc/3.0) which permits unrestricted non-commercial use, distribution, and reproduction in any medium, provided the original work is properly cited. frequently used (6). Kneipp therapy includes five preventive and curative methods created by Sebastian Kneipp, a German priest (5), in which exercise in a forest is one of the five core methods (2). Japan is one of the countries where the forest usage programs for human health are well developed. The Forest Agency of the Japanese government introduced the term "Shinrin-yoku," defined as "taking in the forest atmosphere or forest bathing" in 1982, and instituted the "Therapeutic effects of forests plan" in 2005 (2).

Many studies have shown meaningful physiological effects of forest atmosphere on people $(2,7,8)$. These effects are believed to be achieved by inhaling the forest atmosphere, which includes various phytochemicals mainly produced by trees. The major components of the forest atmosphere are terpenes, which are the largest class of naturally occurring organic compounds (9) with more than 40,000 structures reported so far $(9,10)$. Their basic chemical structure consists of an isoprene unit $\left(\mathrm{C}_{5} \mathrm{H}_{8}\right)(11)$. Depending on the number of isoprene units, terpenes are classified as mono-, sesqui-, and di-terpenes (C10, C15, and C20, respectively) (Fig. 1A) (12). Terpenes have enormous chemical structural diversity that is generated by various terpenoid metabolic pathways as well as the specialized cell types that participate in their biosynthesis (13). The biosynthesis of terpenes uses two common C5 building blocks, dimethylallyl pyrophosphate (DMAPP) and isopentenyl pyrophosphate (IPP), derived from acetyl coenzyme A (14). Head-to-tail condensation of DMAPP and IPP generates the monoterpene precursor, ger- 
(A)

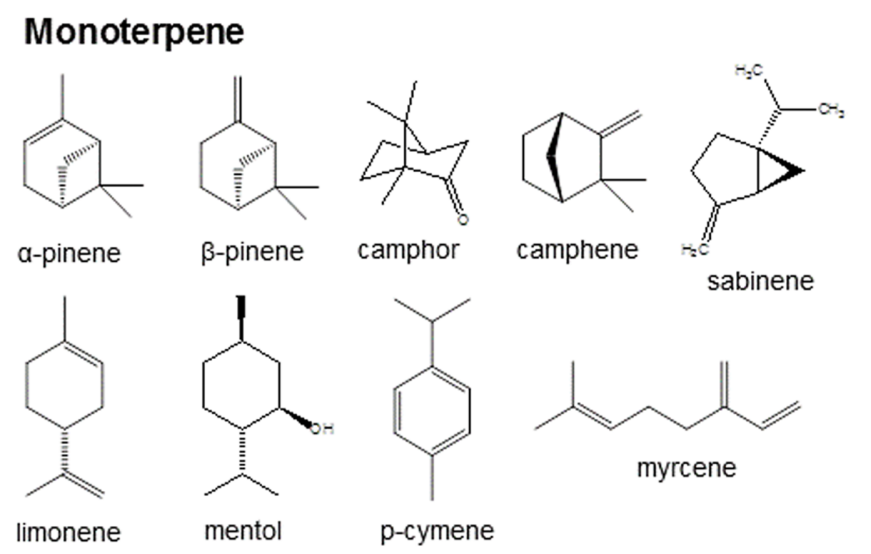

Sesquiterpene<smiles>CC(C)=CC/C=C(\C)C1CC=C(C)CC1</smiles>

bisabolene<smiles>C=CC(C)(O)CCC=C(C)CCC=C(C)C</smiles>

nerolidol
(B)
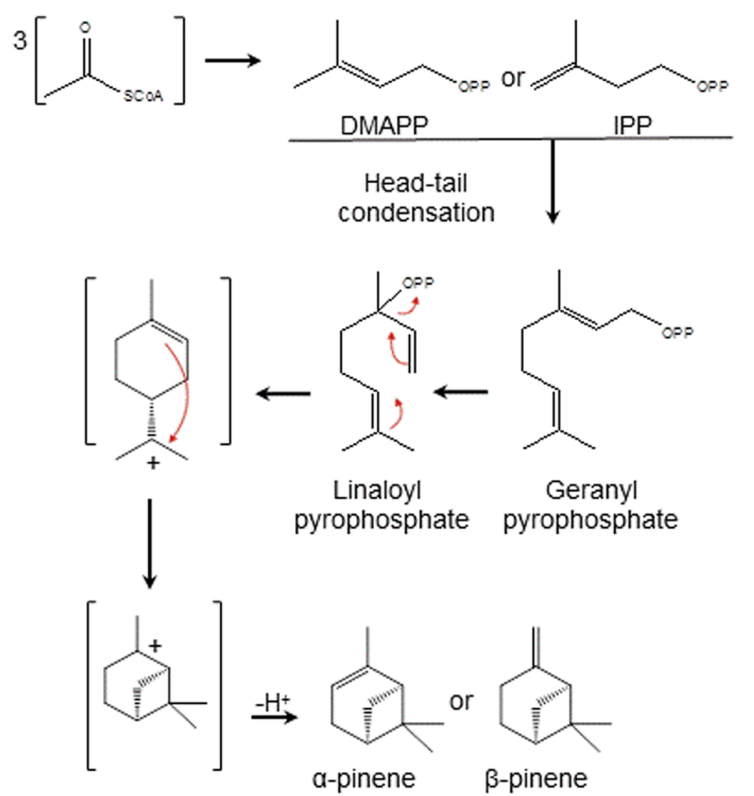

\section{Diterpene}<smiles>CCC(C)CCCC(C)CCCC(C)CCCC(C)C</smiles>

Fig. 1. Structures of various terpenes (A) and terpene biosynthesis pathway for pinenes (B). (A) Depending on the carbon number, terpenes are classified as mono-, sesqui-, and di-terpenes. (B) Using DMAPP and IPP as building blocks, monoterpenes are produced from GPP. Especially, $\alpha$-pinene and $\beta$-pinene are generated via cyclisation of linaloyl pyrophosphate and the loss of a proton from the carbocation equivalent.

anyl pyrophosphate (GPP, C10) (Fig. 1B) (15). Furthermore, sesquiterpenes and diterpenes are created by condensation of additional IPP units to GPP (Fig. 1B) $(15,16)$.

Terpenes are produced by various plants, particularly conifers (13). Many of the terpenes are associated with not only the defense mechanism of the plant against herbivores and the environment $(11,17)$ but also their developmental physiology (9). Korean forests mainly consist of various types of conifers, and many terpenes derived from them have been detected, such as $\alpha$-pinene, $\beta$-pinene, camphor, camphene, sabinene, limonene, menthol, cymene, and myrcene (18). Conifer oleoresins contain monoterpenes (e.g., pinene and camphor) and diterpenes (e.g., taxadiene and phytane) as major components and sesquiterpenes (e.g., nerolidol and (E)- $\alpha$-bisabolene) as minor components (17).

Given that the forest atmosphere is beneficial to human health and that terpenes are the main components of forest aerosols, we reviewed the effects of various terpenes from Korean forests on human health, especially on immunity, cancer, and neuronal health.

\section{TERPENES WITH ANTI-INFLAMMATORY FUNCTION}

Studies in recent decades have demonstrated that terpenes exert anti-inflammatory effects by inhibiting various proinflammatory pathways in ear edema, bronchitis, chronic obstructive pulmonary disease, skin inflammation, and osteoarthritis (19-23).

$\alpha$-Pinene, found in oils of coniferous trees and rosemary, showed anti-inflammatory activity by decreasing the activity of mitogen-activated protein kinases (MAPKs), expression of nuclear factor kappa B (NF- $\mathrm{KB})$, and production of interleukin-6 (IL-6), tumor necrosis factor- $\alpha$ (TNF- $\alpha$ ) and nitric oxide (NO) in lipopolysaccharide (LPS)-induced macrophages (24). In ovalbumin-sensitized mouse model of allergic rhinitis, pretreatment with $\alpha$-pinene decreased clinical symptoms and levels of immunoglobulin E and IL-4 (25). In human chondrocytes, $\alpha$-pinene inhibited IL-1 $\beta$ induced inflammation pathway by suppressing NF- $\mathrm{KB}$, cJun N-terminal kinase (JNK) activation, and expression of 
iNOS and matrix metalloproteinases (MMP)-1 and -13, suggesting its role as an anti-osteoarthritic agent (19). Strong anti-inflammatory activity was observed when $\alpha$-pinene was used in combination with two active ingredients of frankincense, linalool and 1-octanol (22).

Another naturally occurring monoterpene d-limonene was reported to reduce allergic lung inflammation in mice probably via its antioxidant properties (26). It also reduced carrageenan-induced inflammation by reducing cell migration, cytokine production, and protein extravasation (27). Similar to $\alpha$-pinene, $d$-limonene exerted an anti-osteoarthritic effect by inhibiting IL-1 $\beta$-induced NO production in human chondrocytes (28). d-Limonene treatment reduced doxorubicin-induced production of two proinflammatory cytokines, TNF- $\alpha$ and prostaglandin E-2 ( $\left.\mathrm{PGE}_{2}\right)(29)$.

Monoterpene $\mathrm{p}$-cymene treatment reduced elastase-induced lung emphysema and inflammation in mice. It reduced the alveolar enlargement, number of macrophages, and levels of proinflammatory cytokines such as IL-1 $\beta$, IL-6, IL-8, and IL-17 in bronchoalveolar lavage fluid (BALF) (30). Similarly, p-cymene showed a protective effect in a mouse model of LPS-induced acute lung injury by reducing the number of inflammatory cells in the BALF and expression of NF- $\kappa \mathrm{B}$ in the lungs (31) and by reducing production of proinflammatory cytokines and infiltration of inflammatory cells (32). Mechanistically, p-cymene blocks NF- $\kappa \mathrm{B}$ and MAPK signaling pathways. It has been reported that $p-$ cymene reduces production of TNF- $\alpha$, IL- 6 , and IL- $\beta$ in LPS-treated RAW 264.7 macrophages. In C57BL/6 mice, TNF- $\alpha$ and IL-1 $\beta$ were downregulated and IL-10 was upregulated by p-cymene treatment. It also inhibited LPS-induced activation of ERK 1/2, p38, JNK, and I $\mathrm{BB} \alpha(32,33)$.

Treatment with linalool, a natural compound found in essential oils of aromatic plants, inhibited cigarette smokeinduced acute lung inflammation by inhibiting infiltration of inflammatory cells and production of TNF- $\alpha$, IL-6, IL$1 \beta$, IL-8, and monocyte chemoattractant protein - 1 (MCP1 ), as well as NF- $\kappa \mathrm{B}$ activation (20). In another lung injury model, linalool attenuated lung histopathologic changes in LPS-induced mice. In in vitro experiments, linalool reduced production of TNF- $\alpha$ and IL- 6 and blocked phosphorylation of $\mathrm{I} \kappa \mathrm{B} \alpha$ protein, $\mathrm{p} 38$, and JNK in LPS-stimulated RAW 264.7 macrophages (34). Similarly, linalool inhibited production of TNF- $\alpha$, IL-1 $\beta$, NO, and PGE 2 in LPS-stimulated microglia cells (35). Li et al. (35) showed that the antiinflammatory effect of linalool is involved in activation of Nrf2/heme oxygenase-1 (HO-1) signaling pathway. Frankincense oil extract, which contains linalool, exhibited antiinflammatory and analgesic effects in a xylene-induced ear edema model and a formalin-inflamed hind paw model by inhibiting COX-2 (22).

The monoterpene $\gamma$-terpinene, present in the essential oil of many plants including Eucalyptus, reduced the acute inflammatory response. It reduced carrageenan-induced paw edema, migration of neutrophil into lung tissue, and IL-1 $\beta$ and TNF- $\alpha$ production and inhibited fluid extravasation (36). Terpinene-containing essential oil from Liquidambar formosana leaves reduced inflammatory response in LPSstimulated mouse macrophages by reducing reactive oxygen species (ROS), JNK, ERK, p38 MAP kinase, and NF$\kappa \mathrm{B}$ (37). Another terpinene-containing essential oil from Citrus unshiu flower or fingered citron (C. medica L. var. sarcodactylis) reduced LPS-stimulated $\mathrm{PGE}_{2}$ and $\mathrm{NO}$ production in RAW 264.7 cells. Furthermore, production of inflammatory cytokines, such as IL-1 $\beta$, TNF- $\alpha$, and IL-6, was also reduced in macrophages $(38,39)$.

Borneol, a bicyclic monoterpene present in Artemisia, Blumea, and Kaempferia, has been used in traditional medicine. Borneol alleviated acute lung inflammation by reducing inflammatory infiltration, histopathological changes, and cytokine production in LPS-stimulated mice. It suppressed phosphorylation of NF- $\kappa \mathrm{B}, \mathrm{I} \kappa \mathrm{B} \alpha, \mathrm{p} 38, \mathrm{JNK}$, and ERK (40). Oral administration and intrathecal injection of borneol showed antihyperalgesic effects on inflammatory pain in complete Freund's adjuvant-induced hypersensitive animal models by enhancing GABA $_{\mathrm{A}} \mathrm{R}$ (Gamma-Aminobutyric Acid Type A Receptor)-mediated GABAergic transmission (41). Borneol inhibited migration of leukocytes into the peritoneal cavity in carrageenan-stimulated mice, suggesting its anti-inflammatory function (42). In addition, borneol inhibited TRPA1, a cation channel that is involved in inflammation and noxious-pain sensing, suggesting that its use as an anti-inflammatory agent for neuropathic-pain and trigeminal neuralgia (43).

A natural sesquiterpene $\beta$-caryophyllene (BCP) was reported to protect against neuroinflammation in a rat model of Parkinson's disease (PD) by attenuating production of proinflammatory cytokines and inflammatory mediators such as COX-2 and iNOS (44). Chronic treatment with BCP attenuated alcohol-induced liver injury and inflammation by reducing the proinflammatory phenotypic switch of hepatic macrophages and neutrophil infiltration. The beneficial effects of BCP on liver injury are mediated by cannabinoid 2 (CB2) receptor activation (45). Prolonged administration of BCP reduced proinflammatory cytokines in pancreatic tissue of streptozotocin-induced diabetic rats (46). BCP reduced expression of Toll-like receptor 4 and macrophage inflammatory protein-2, and phosphorylation of ERK, p38, $\mathrm{JNK}$, and NF- $\kappa \mathrm{B}$ in D-galactosamine and LPS-induced liver injury mouse model (47).

Besides the aforementioned terpenes, anti-inflammatory effects have been reported with sabinene itself or sabinenecontaining oil $(48,49)$, bornyl acetate $(50)$ and myrcene $(28)$.

\section{TERPENES AND TUMOR}

Tumorigenesis is a multifaceted process, the progression of which is associated with several hallmarks, including 
uncontrolled cell growth, dysregulation of apoptosis, activation of invasion, induction of angiogenesis, and metastasis. Terpenes have been shown to exert anti-tumorigenic effects against such processes in a number of in vivo and in vitro systems, thus suggesting their potential uses as chemotherapeutic agents for treating tumors.

A number of monoterpenes have been reported to exert chemopreventive effects against tumors (51). Of these, the anti-tumorigenic activity of d-limonene is well-established. Numerous studies have demonstrated the protective effects of d-limonene against chemical-induced tumors in various tissue types such as breast, intestine, pancreas, liver, and colon (52-57). Lu et al. (57) revealed that d-limonene could inhibit the proliferation of human gastric cancer cells by inducing apoptosis. Later, it was demonstrated that apoptosis of tumor cells by d-limonene could be mediated by the mitochondrial death pathway via activated caspases and PARP cleavage as well as by the suppression of the PI3K/ Akt pathway $(58,59)$. In addition, positive effects on NK (Natural Killer) activities were demonstrated not only in the in vitro treatment of tumor cell lines with monoterpenes released from trees, such as d-limonene and $\alpha$-pinene, but also in forest bathing trips by increasing intracellular levels of anti-tumor proteins such as perforin, granulysin, and granzymes A/B (60).

Anti-tumor effects of pinenes are well established on tumor lymphocytes as well as tumor cell lines (61). Matsuo et al. (62) identified proapoptotic and anti-metastatic activities of $\alpha$-pinene in a melanoma model. Later, it was revealed in human hepatoma Bel-7402 cells that the proapoptotic effect of $\alpha$-pinene is associated with induction of $\mathrm{G} 2 / \mathrm{M}$ cell cycle arrest (63). In addition, $\alpha$-pinene triggers oxidative stress signaling pathways in A549 and HepG2 cells (64). However, Kusuhara et al. (65) reported that mice kept in a setting enriched with $\alpha$-pinene showed reduction in melanoma sizes, while in vitro treatment of melanoma cells with $\alpha$-pinene had no inhibitory effect on cell proliferation, suggesting that the in vivo result may not be due to a direct effect of $\alpha$-pinene. Investigation of $\beta$-pinene also revealed its cytotoxic activity against cancer and normal cell lines with a more pronounced effect on neoplastic cells in the majority of cases, showing acceptable chemotherapeutic potency $(66,67)$.

Perillyl alcohol is a naturally occurring monoterpene, and a metabolite of limonene. Despite preclinical evidence of anticancer activity, perillyl alcohol appeared to have no clinical antitumor activity upon oral administration to patients with advanced colorectal carcinoma (68). However, currently, it is under preclinical development as a potential clinical treatment for patients with brain tumor (69). Perillic acid is a major metabolite of perillyl alcohol. Upon examining the effects of perillic acid on lung metastasis induced by melanoma cells in mice, it was observed that administration of perillic acid remarkably reduced the metastatic tumor nod- ule formation by exerting an inhibitory effect on cell growth by $\mathrm{G} 1$ arrest $(70,71)$.

p-Cymene has been reported to have cytotoxic effects on tumor cell lines (72). Recently, Li et al. (73) evaluated beneficial effects of $\mathrm{p}$-cymene on in vitro TPA-augmented invasiveness of HT- 1080 cells, and found that it inhibits MMP-9 expression, but enhances TIMP-1 production along with the suppression of ERK1/2 and p38 MAPK signal pathways in tumor cells, suggesting that p-cymene is an effective candidate for the prevention of tumor invasion and metastasis.

Myrcene, the acyclic monoterpene, also exhibits significant antiproliferative and cytotoxic effects in various tumor cell lines such as MCF-7 (breast carcinoma), HeLa (human cervical carcinoma), A549 (human lung carcinoma), HT-29 (human colon adenocarcinoma), P388 (leukemia), and Vero (monkey kidney) as well as mouse macrophages $(74,75)$. Essential oil from Vepris macrophylla demonstrated a strong cytotoxic effect, suggesting that the effect may be attributed to the presence of specific components, among which is myrcene (76).

Terpenes with more complex structures than monoterpenes, including sesquiterpenoids derived from sesquiterpenes by biochemical modifications, have demonstrated anticancer ability as well. The anticancer effect of various sesquiterpenoids is mediated via inhibition of inflammatory responses, prevention of metastasis, and induction of apoptosis (77). $\alpha$-Caryophyllene, known as humulene, is a naturally occurring monocyclic sesquiterpene. BCP, an isomer of $\alpha$-caryophyllene, has been identified as an active component of an essential oil mixture that not only prevents solid tumor growth and proliferation of cancer cell lines but also inhibits lymph node metastasis of melanoma cells in high-fat diet-induced obese mice $(78,79)$. Sarvmeili et al . (80) reported that Pinus eldarica essential oil, of which BCP was the major component, exerts cytotoxic effects on HeLa and MCF-7 cell lines.

As described above, numerous in vitro and in vivo experimental results have demonstrated that the toxicity of terpene affects mainly cancer cells without harming healthy ones, confirming their efficiency in chemotherapeutic treatment of cancer. Thus, it is noteworthy that the use of terpene and its derivatives can be considered to potentiate the action of existing conventional therapies $(81,82)$.

\section{TERPENES AND NEURONAL HEALTH}

Numerous studies have shown that essential oils derived from various plants have neuroprotective effects against neurodegenerative conditions in vivo and in vitro (83-90). Therefore, as a main component of plant essential oils, terpenes may be beneficial to human neuronal health. However, only few studies have focused on the beneficial effects of terpene components of plant essential oils on neuronal health.

So far, several terpenes, produced by a variety of plants, 
Table 1. Studies reporting the effects of terpenes on human health

\begin{tabular}{|c|c|c|c|c|}
\hline Class & Terpene & Structure & Effect & Related literature \\
\hline \multirow[t]{12}{*}{ Mono- } & 1,8-Cineole & & $\begin{array}{l}\text { Antioxidation } \\
\text { Neuroprotection }\end{array}$ & $\begin{array}{l}(106) \\
(106)\end{array}$ \\
\hline & 1-Octanol & & Anti-inflammation & (73) \\
\hline & Borneol & & $\begin{array}{l}\text { Anti-inflammation } \\
\text { Antioxidation } \\
\text { Neuroprotection }\end{array}$ & $\begin{array}{l}(40-43) \\
(91-101) \\
(91-94)\end{array}$ \\
\hline & Bornyl acetate & & Anti-inflammation & $(50)$ \\
\hline & Cymene & & $\begin{array}{l}\text { Anti-inflammation } \\
\text { Anti-cancer } \\
\text { Neuroprotection }\end{array}$ & $\begin{array}{l}(30-33) \\
(72,73) \\
(107)\end{array}$ \\
\hline & Limonene & & $\begin{array}{l}\text { Anti-inflammation } \\
\text { Antioxidation } \\
\text { Anti-cancer }\end{array}$ & $\begin{array}{l}(26-29) \\
(52-60) \\
(20,22,34,35)\end{array}$ \\
\hline & Linalool & & Anti-inflammation & $(20,22,34,35)$ \\
\hline & Myrcene & & $\begin{array}{l}\text { Anti-inflammation } \\
\text { Anti-cancer }\end{array}$ & $\begin{array}{l}(28) \\
(74-76)\end{array}$ \\
\hline & Perillyl alcohol & & Anti-cancer & $(68-71)$ \\
\hline & Pinene & & $\begin{array}{l}\text { Anti-inflammation } \\
\text { Anti-cancer } \\
\text { Antioxidation } \\
\text { Neuroprotection }\end{array}$ & $\begin{array}{l}(19,22,24,25) \\
(60-66) \\
(105) \\
(106)\end{array}$ \\
\hline & Sabinene & & Anti-inflammation & $(48,49)$ \\
\hline & Terpinene & & Anti-inflammation & $(36-39)$ \\
\hline Sesqui- & Caryophyllene & & $\begin{array}{l}\text { Anti-inflammation } \\
\text { Anti-cancer } \\
\text { Antioxidation } \\
\text { Neuroprotection }\end{array}$ & $\begin{array}{l}(31,44-47) \\
(78-80) \\
(44,103) \\
(44,103-105)\end{array}$ \\
\hline
\end{tabular}


have been associated with neuronal health. Among those, borneol is a bicyclic monoterpene present in several medicinal plants (91-94). Previous studies showed that borneol has free radical scavenging activity (95) and is a major component of essential oil of SuHeXiang Wan (92) whose neuroprotective function has been reported in in vivo and in vitro models of Alzheimer's disease (AD) (96-99). Moreover, a recent study showed that borneol exerts a neuroprotective effect against $\beta$-amyloid $(A \beta)$ cytotoxicity via upregulation of nuclear translocation of $\mathrm{Nrf} 2$ and expression of $\mathrm{Bcl}-2$ (100). In addition, treatment with isoborneol, a monoterpenoid alcohol, significantly reduced 6-hydroxydopamineinduced ROS generation and cell death in human neuroblastoma SH-SY5Y cells, suggesting that isoborneol may be a potential therapeutic agent for treatment of neurodegenerative diseases associated with oxidative stress (101). Salvianic borneol ester, a new compound synthesized from salvianic acid $\mathrm{A}$ and borneol, also exerts anti-amyloid and neuroprotective effects in both SH-SY5Y cells and motor neuron hybridoma VSC 4.1 cells (102).

$\mathrm{BCP}$ also has neuroprotective functions. It has been reported that BCP has antioxidant effects (103), and functions as a regulator of several neuronal receptors and shows various pharmacological activities including neuroprotection (104). Neuroprotective effects of BCP have been reported in both $\mathrm{AD}$ and PD animal models. Oral treatment with $\mathrm{BCP}$ prevented AD-like phenotype such as cognitive impairment and activation of inflammation through $\mathrm{CB} 2$ receptor activation and the PPAR $\gamma$ pathway (105). As described above, BCP administration also exerts neuroprotective effects in rotenone-challenged rat model of PD by reducing neuroinflammation (44).

Other monoterpenes such as $\alpha$-pinene and 1, 8-cineole also exert neuroprotective effects by regulating gene expression. They protected PC12 cells against oxidative stressinduced apoptosis through ROS scavenging and induction of nuclear Nrf2 factor followed by enhanced expression of antioxidant enzymes including catalase, superoxide dismutase, glutathione peroxidase, glutathione reductase, and HO-1 (106). Similarly, p-cymene has cholinergic effects through regulation of expression of several genes in Caenorhabditis elegans (107). Given that terpenes are major components of essential oils of various medicinal plants with neuroprotective functions, studies to find the beneficial roles of terpenes in neurodegenerative diseases will provide a promising way to develop therapeutics.

\section{CONCLUSION AND PERSPECTIVES}

Essential oils obtained from plants have been used in diverse traditional medicines because of their broad beneficial effects on human health (108). To date, many terpenes from essential oils as well as forest bathing have been reported to exhibit strong biological activities. This review categorized the terpenes that have presented important results in cell and animal systems according to their anti-inflammatory, anti-tumorigenic, or neuroprotective activities (Table 1). Although data elucidating the possible action mechanisms of these compounds are increasing, numerous studies still present only preliminary screening results. Thus, to investigate the future chemotherapeutic uses of terpenes, it is necessary to explore further the detailed action mechanisms including signaling pathways that are associated with their biological functions. In addition, understanding of the relationship between the diverse chemical structures of terpenes and the in vivo physiological roles of these compounds may provide critical insights for the future development of therapeutics with enhanced selectivity and specificity.

So far, many studies have extensively reported the pharmaceutical activities of monoterpenes among the terpenes. Monoterpenes, formed from the coupling of two isoprene units (C10), are the major molecules consisting $90 \%$ of the essential oils (109). However, in recent years, small subgroups of other terpenes and terpenoids that exhibit diverse biological activities have been isolated or synthesized, providing a source of novel chemotherapeutic molecules. The use of various terpenes in clinical trials is currently limited due to insufficient data from human studies. However, their use as potent chemotherapeutic compounds alone, as well as in combination with previously proven chemotherapeutic drugs, to increase effectiveness and decrease doses is expected to increase as data on their safety and efficacy in in vivo and in vitro systems are accumulated.

\section{CONFLICT OF INTEREST}

The authors declare that they have no competing interests.

\section{ACKNOWLEDGMENTS}

This research was supported by the National Research Foundation of Korea (NRF) funded by the Ministry of Science, ICT and Future Planning (NRF-2016M3C1B6928005).

\section{REFERENCES}

1. Frumkin, H. (2001) Beyond toxicity: human health and the natural environment. Am. J. Prev. Med., 20, 234-240.

2. Tsunetsugu, Y., Park, B.J. and Miyazaki, Y. (2010) Trends in research related to "Shinrin-yoku" (taking in the forest atmosphere or forest bathing) in Japan. Environ. Health Prev. Med., 15, 27-37.

3. Seo, S.C., Park, S.J., Park, C.W., Yoon, W.S., Choung, J.T. and Yoo, Y. (2015) Clinical and immunological effects of a forest trip in children with asthma and atopic dermatitis. Iran J. Allergy Asthma Immunol., 14, 28-36.

4. Douglass, R.W. (1982) Forest recreation (3rd edition), Pergamon Press. 
5. Spievogel, I. and Spalek, K. (2012) Medicinal plants uesed in pediatric prophylactic method of Sebastian Kneipp. Nat. J., 45, 9-18.

6. Joos, S., Rosemann, T., Szecsenyi, J., Hahn, E.G., Willich, S.N. and Brinkhaus, B. (2006) Use of complementary and alternative medicine in Germany: a survey of patients with inflammatory bowel disease. BMC Complement. Altern. Med., 6, 19.

7. Park, B.J., Tsunetsugu, Y., Kasetani, T., Kagawa, T. and Miyazaki, Y. (2010) The physiological effects of Shinrin-yoku (taking in the forest atmosphere or forest bathing): evidence from field experiments in 24 forests across Japan. Environ. Health Prev. Med., 15, 18-26.

8. Song, C., Ikei, H. and Miyazaki, Y. (2016) Physiological effects of nature therapy: A review of the research in Japan. Int. J. Environ. Res. Public Health, 13, E781.

9. Gershenzon, J. and Dudareva, N. (2007) The function of terpene natural products in the natural world. Nat. Chem. Biol., 3, 408-414.

10. Chappell, J. (2002) The genetics and molecular genetics of terpene and sterol origami. Curr. Opin. Plant Biol., 5, 151-157.

11. Mewalal, R., Rai, D.K., Kainer, D., Chen, F., Külheim, C., Peter, G.F. and Tuskan, G.A. (2016) Plant-derived terpenes: A feedstock for specialty biofuels. Trends Biotechnol., S01677799(16)30128-7.

12. Kirby, J. and Keasling, J.D. (2009) Biosynthesis of plant isoprenoids: perspectives for microbial engineering. Annu. Rev. Plant Biol., 60, 335-355.

13. Zulak, K.G. and Bohlmann, J. (2010) Terpenoid biosynthesis and specialized vascular cells of conifer defense. J. Integr. Plant Biol., 52, 86-97.

14. Lange, B.M. and Ahkami, A. (2013) Metabolic engineering of plant monoterpenes, sesquiterpenes and diterpenes: current status and future opportunities. Plant Biotechnol. J., 11, 169-196.

15. Dubey, V.S., Bhalla, R. and Luthra, R. (2003) An overview of the non-mevalonate pathway for terpenoid biosynthesis in plants. J. Biosci., 28, 637-646.

16. Matsuba, Y., Nguyen, T.T., Wiegert, K., Falara, V., GonzalesVigil, E., Leong, B., Schäfer, P., Kudrna, D., Wing, R.A., Bolger, A.M., Usadel, B., Tissier, A., Fernie, A.R., Barry, C.S. and Pichersky, E. (2013) Evolution of a complex locus for terpene biosynthesis in solanum. Plant Cell, 25, 2022-2036.

17. Martin, D.M., Gershenzon, J. and Bohlmann, J. (2003) Induction of volatile terpene biosynthesis and diurnal emission by methyl jasmonate in foliage of Norway spruce. Plant Physiol., 132, 1586-1599.

18. Lee, D.H., Kim, M.H., Park, O.H., Park, KS., An, S.S., Seo, H.J., Jin, S.H., Jeong, W.S., Kang, Y.J., An, K.W. and Kim, E.S. (2013) A study on the distribution characteristics of terpene at the main trails of Mt. Mudeung. J. Environ. Health Sci., 39, 211-222.

19. Rufino, A.T., Ribeiro, M., Judas, F., Salgueiro, L., Lopes, M.C., Cavaleiro, C. and Mendes, A.F. (2014) Anti-inflammatory and chondroprotective activity of $(+)-\alpha$-pinene: structural and enantiomeric selectivity. J. Nat. Prod., 77, 264-269.

20. Ma, J., Xu, H., Wu, J., Qu, C., Sun, F. and Xu, S. (2015) Linalool inhibits cigarette smoke-induced lung inflammation by inhibiting $\mathrm{NF}-\kappa \mathrm{B}$ activation. Int. Immunopharmacol., 29, 708-713.

21. Rodrigues, K.A., Amorim, L.V., Dias, C.N., Moraes, D.F.C.,
Carneiro, S.M. and Carvalho, F.A. (2015) Syzygium cumini (L.) Skeels essential oil and its major constituent $\alpha$-pinene exhibit anti-Leishmania activity through immunomodulation in vitro. J. Ethnopharmacol., 160, 32-40.

22. Li, X.J., Yang, Y.J., Li, Y.S., Zhang, W.K. and Tang, H.B. (2016) $\alpha$-Pinene, linalool and 1-octanol contribute to the topical anti-inflammatory and analgesic activities of frankincense by inhibiting COX-2. J. Ethnopharmacol., 179, 22-26.

23. Yu, P.J., Wan, L.M., Wan, S.H., Chen, W.Y., Xie, H., Meng, D.M., Zhang, J.J. and Xiao, X.L. (2016) Standardized myrtol attenuates lipopolysaccharide induced acute lung injury in mice. Pharm. Biol., 54, 3211-3216.

24. Kim, D.S., Lee, H.J., Jeon, Y.D., Han, Y.H., Kee, J.Y., Kim, H.J., Shin, H.J., Kang, J., Lee, B.S., Kim, S.H., Kim, S.J., Park, S.H., Choi, B.M., Park, S.J., Um, J.Y. and Hong, S.H. (2015) Alpha-pinene exhibits anti-inflammatory activity through the suppression of MAPKs and the NF-kB pathway in mouse peritoneal macrophages. Am. J. Chin. Med., 43, 731-742.

25. Nam, S.Y., Chung, C.k., Seo, J.H., Rah, S.Y., Kim, H.M. and Jeong, H.J. (2014) The therapeutic efficacy of $\alpha$-pinene in an experimental mouse model of allergic rhinitis. Int. Immunopharmacol., 23, 273-282.

26. Hansen, J.S., Nørgaard, A.W., Koponen, I.K., Sørli, J.B., Paidi, M.D., Hansen, S.W., Clausen, P.A., Nielsen, G.D., Wolkoff, P. and Larsen, S.T. (2016) Limonene and its ozoneinitiated reaction products attenuate allergic lung inflammation in mice. J. Immunotoxicol., 13, 793-803.

27. Amorim, J.L., Simas, D.L.R., Pinheiro, M.M., Moreno, D.S., Alviano, C.S., da Silva, A.J. and Fernandes, P.D. (2016) Antiinflammatory properties and chemical characterization of the essential oils of four citrus species. PLOS ONE, 11, e0153643.

28. Rufino, A.T., Ribeiro, M., Sousa, C., Judas, F., Salgueiro, L., Cavaleiro, C. and Mendes, A.F. (2015) Evaluation of the antiinflammatory, anti-catabolic and pro-anabolic effects of Ecaryophyllene, myrcene and limonene in a cell model of osteoarthritis. Eur. J. Pharmacol., 750, 141-150.

29. Rehman, M.U., Tahir, M., Khan, A.Q., Khan, R., Oday-OHamiza, Lateef, A., Hassan, S.K., Rashid, S., Ali, N., Zeeshan, M. and Sultana, S. (2014) D-limonene suppresses doxorubicin-induced oxidative stress and inflammation via repression of COX-2, iNOS and NFKB in kidneys of Wistar rats. Exp. Biol. Med. (Maywood), 239, 465-476.

30. Games, E., Guerreiro, M., Santana, F.R., Pinheiro, N.M., de Oliveira, E.A., Lopes, F.D., Olivo, C.R., Tibério, I.F., Martins, M.A., Lago, J.H. and Prado, C.M. (2016) Structurally related monoterpenes p-Cymene, carvacrol and thymol isolated from essential oil from leaves of lippia sidoides cham. (Verbenaceae) protect mice against elastase-induced emphysema. Molecules, 21, E1390.

31. Chen, L., Zhao, L., Zhang, C. and Lan, Z. (2014) Protective effect of p-cymene on lipopolysaccharide-induced acute lung injury in mice. Inflammation, 37, 358-364.

32. Xie, G., Chen, N., Soromou, L.W., Liu, F., Xiong, Y., Wu, Q., Li, H., Feng, H. and Liu, G. (2012) p-Cymene protects mice against lipopolysaccharide-induced acute lung injury by inhibiting inflammatory cell activation. Molecules, 17, 8159-8173.

33. Zhong, W., Chi, G., Jiang, L., Soromou, L.W., Chen, N., Huo, M., Guo, W., Deng, X. and Feng, H. (2013) p-Cymene modulates in vitro and in vivo cytokine production by inhibiting 
MAPK and NF- $\mathrm{KB}$ activation. Inflammation, 36, 529-537.

34. Huo, M., Cui, X., Xue, J., Chi, G., Gao, R., Deng, X., Guan, S., Wei, J., Soromou, L.W., Feng, H. and Wang, D. (2013) Anti-inflammatory effects of linalool in RAW 264.7 macrophages and lipopolysaccharide-induced lung injury model. $J$. Surg. Res., 180, e47-e54.

35. Li, Y., Lv, O., Zhou, F., Li, Q., Wu, Z. and Zheng, Y. (2015) Linalool inhibits LPS-induced inflammation in BV2 microglia cells by activating Nrf2. Neurochem. Res., 40, 1520-1525.

36. de Oliveira Ramalho, T.R., de Oliveira, M.T., de Araujo Lima, A.L., Bezerra-Santos, C.R. and Piuvezam, M.R. (2015) Gamma-terpinene modulates acute inflammatory response in mice. Planta Med., 81, 1248-1254.

37. Hua, K.F., Yang, T.J., Chiu, H.W. and Ho, C.L. (2014) Essential oil from leaves of Liquidambar formosana ameliorates inflammatory response in lipopolysaccharide-activated mouse macrophages. Nat. Prod. Commun., 9, 869-872.

38. Kim, K.N., Ko, Y.J., Yang, H.M., Ham, Y.M., Roh, S.W., Jeon, Y.J., Ahn, G., Kang, M.C., Yoon, W.J., Kim, D. and Oda, T. (2013) Anti-inflammatory effect of essential oil and its constituents from fingered citron (Citrus medica $\mathrm{L}$. var. sarcodactylis) through blocking JNK, ERK and NF- $\mathrm{KB}$ signaling pathways in LPS-activated RAW 264.7 cells. Food Chem. Toxicol., 57, 126-131.

39. Kim, M.J., Yang, K.W., Kim, S.S., Park, S.M., Park, K.J., Kim, K.S., Choi, Y.H., Cho, K.K. and Hyun, C.G. (2014) Chemical composition and anti-inflammation activity of essential oils from Citrus unshiu flower. Nat. Prod. Commun., 9, 727-730.

40. Zhong, W., Cui, Y., Yu, Q., Xie, X., Liu, Y., Wei, M., Ci, X. and Peng, L. (2014) Modulation of LPS-stimulated pulmonary inflammation by borneol in murine acute lung injury model. Inflammation, 37, 1148-1157.

41. Jiang, J., Shen, Y.Y., Li, J., Lin, Y.H., Luo, C.X. and Zhu, D.Y. (2015) (+)-Borneol alleviates mechanical hyperalgesia in models of chronic inflammatory and neuropathic pain in mice. Eur. J. Pharmacol., 757, 53-58.

42. Almeida, J.R., Souza, G.R., Silva, J.C., Saraiva, S.R., Júnior, R.G., Quintans Jde, S., Barreto Rde, S., Bonjardim, L.R., Cavalcanti, S.C. and Quintans, L.J., Jr. (2013) Borneol, a bicyclic monoterpene alcohol, reduces nociceptive behavior and inflammatory response in mice. ScientificWorldJournal, 2013, 808460

43. Sherkheli, M.A., Schreiner, B., Haq, R., Werner, M. and Hatt, H. (2015) Borneol inhibits TRPA1, a proinflammatory and noxious pain-sensing cation channel. Pak. J. Pharm. Sci., 28, 1357-1363.

44. Ojha, S., Javed, H., Azimullah, S. and Haque, M.E. (2016) $\beta$-Caryophyllene, a phytocannabinoid attenuates oxidative stress, neuroinflammation, glial activation and salvages dopaminergic neurons in a rat model of Parkinson disease. Mol. Cell. Biochem., 418, 59-70.

45. Varga, Z.V., Matyas, C., Erdelyi, K., Cinar, R., Nieri, D., Chicca, A., Nemeth, B.T., Paloczi, J., Lajtos, T., Corey, L., Hasko, G., Gao, B., Kunos, G., Gertsch, J. and Pacher, P. (2017) Beta-caryophyllene protects against alcoholic steatohepatitis by attenuating inflammation and metabolic dysregulation in mice. Br. J. Pharmacol. [Epub ahead of print].

46. Basha, R.H. and Sankaranarayanan, C. (2016) $\beta$-Caryophyllene, a natural sesquiterpene lactone attenuates hyperglycemia mediated oxidative and inflammatory stress in experimental diabetic rats. Chem. Biol. Interact., 245, 50-58.

47. Cho, H.I., Hong, J.M., Choi, J.W., Choi, H.S., Kwak, J.H., Lee, D.U., Lee, S.K. and Lee, S.M. (2015) $\beta$-Caryophyllene alleviates d-galactosamine and lipopolysaccharide-induced hepatic injury through suppression of the TLR4 and RAGE signaling pathways. Eur. J. Pharmacol., 764, 613-621.

48. Kim, M.J., Yang, K.W., Kim, S.S., Park, S.M., Park, K.J., Kim, K.S., Choi, Y.H., Cho, K.K., Lee, N.H. and Hyun, C.G. (2013) Chemical composition and anti-inflammatory effects of essential oil from Hallabong flower. EXCLI J., 12, 933-942.

49. Chaiyana, W., Anuchapreeda, S., Leelapornpisid, P., Phongpradist, R., Viernstein, H. and Mueller, M. (2016) Development of microemulsion delivery system of essential oil from Zingiber cassumunar Roxb. Rhizome for improvement of stability and anti-inflammatory activity. AAPS PharmSciTech, 1-11.

50. Yang, H., Zhao, R., Chen, H., Jia, P., Bao, L. and Tang, H. (2014) Bornyl acetate has an anti-inflammatory effect in human chondrocytes via induction of IL-11. IUBMB Life, 66, 854-859.

51. Sobral, M.V., Xavier, A.L., Lima, T.C. and de Sousa, D.P. (2014) Antitumor activity of monoterpenes found in essential oils. ScientificWorldJournal, 2014, 953451.

52. Broitman, S.A., Wilkinson, J., 4th, Cerda, S. and Branch, S.K. (1996) Effects of monoterpenes and mevinolin on murine colon tumor CT-26 in vitro and its hepatic "Metastases" in vitro. Adv. Exp. Med. Biol., 401, 111-130.

53. Uedo, N., Tatsuta, M., Iishi, H., Baba, M., Sakai, N., Yano, H. and Otani, T. (1999) Inhibition by d-limonene of gastric carcinogenesis induced by N-methyl-N'-nitro-N-nitrosoguanidine in Wistar rats. Cancer Lett., 137, 131-136.

54. Stratton, S., Dorr, R. and Alberts, D. (2000) The state-of-theart in chemoprevention of skin cancer. Eur. J. Cancer, 36, 1292-1297.

55. Kaji, I., Tatsuta, M., Iishi, H., Baba, M., Inoue, A. and Kasugai, H. (2001) Inhibition by D-limonene of experimental hepatocarcinogenesis in Sprague-Dawley rats does not involve p21ras plasma membrane association. Int. J. Cancer, 93, 441-444.

56. Guyton, K.Z. and Kensler, T.W. (2002) Prevention of liver cancer. Curr. Oncol. Rep., 4, 464-470.

57. Lu, X.G., Zhan, L.B., Feng, B.A., Qu, M.Y., Yu, L.H. and Xie, J.H. (2004) Inhibition of growth and metastasis of human gastric cancer implanted in nude mice by d-limonene. World $J$. Gastroenterol., 10, 2140-2144.

58. Ji, J., Zhang, L., Wu, Y.Y., Zhu, X.Y., Lv, S.Q. and Sun, X.Z. (2006) Induction of apoptosis by d-limonene is mediated by a caspase-dependent mitochondrial death pathway in human leukemia cells. Leuk. Lymphoma, 47, 2617-2624.

59. Jia, S.S., Xi, G.P., Zhang, M., Chen, Y.B., Lei, B., Dong, X.S. and Yang, Y.M. (2013) Induction of apoptosis by D-limonene is mediated by inactivation of Akt in LS174T human colon cancer cells. Oncol. Rep., 29, 349-354.

60. Li, Q. (2010) Effect of forest bathing trips on human immune function. Environ. Health Prev. Med., 15, 9-17.

61. Bansal, A., Moriarity, D.M., Takaku, S. and Setzer, W.N. (2007) Chemical composition and cytotoxic activity of the leaf essential oil of Ocotea tonduzii from Monteverde, Costa Rica. Nat. Prod. Commun., 2, 781-784.

62. Matsuo, A.L., Figueiredo, C.R., Arruda, D.C., Pereira, F.V., Scutti, J.A., Massaoka, M.H., Travassos, L.R., Sartorelli, P. 
and Lago, J.H. (2011) $\alpha$-Pinene isolated from Schinus terebinthifolius Raddi (Anacardiaceae) induces apoptosis and confers antimetastatic protection in a melanoma model. Biochem. Biophys. Res. Commun., 411, 449-454.

63. Chen, W., Liu, Y., Li, M., Mao, J., Zhang, L., Huang, R., Jin, $X$. and Ye, L. (2015) Anti-tumor effect of $\alpha$-pinene on human hepatoma cell lines through inducing G2/M cell cycle arrest. J. Pharmacol. Sci., 127, 332-338.

64. Jin, K.S., Bak, M.J., Jun, M., Lim, H.J., Jo, W.K. and Jeong, W.S. (2010) $\alpha$-Pinene triggers oxidative stress and related signaling pathways in A549 and HepG2 cells. Food Sci. Biotechnol., 19, 1325-1332.

65. Kusuhara, M., Urakami, K., Masuda, Y., Zangiacomi, V., Ishii, H., Tai, S., Maruyama, K. and Yamaguchi, K. (2012) Fragrant environment with $\alpha$-pinene decreases tumor growth in mice. Biomed. Res., 33, 57-61.

66. Bakarnga-Via, I., Hzounda, J.B., Fokou, P.V.T., Tchokouaha, L.R.Y., Gary-Bobo, M., Gallud, A., Garcia, M., Walbadet, L., Secka, Y., Dongmo, P.M.J., Boyom, F.F. and Menut, C. (2014) Composition and cytotoxic activity of essential oils from Xylopia aethiopica (Dunal) A. Rich, Xylopia parviflora (A. Rich) Benth. and Monodora myristica (Gaertn) growing in chad and cameroon. BMC Complement. Altern. Med., 14, 125.

67. Li, Y.L., Yeung, C.M., Chiu, L., Cen, Y.Z. and Ooi, V.E. (2009) Chemical composition and antiproliferative activity of essential oil from the leaves of a medicinal herb, Schefflera heptaphylla. Phytother. Res., 23, 140-142.

68. Meadows, S.M., Mulkerin, D., Berlin, J., Bailey, H., Kolesar, J., Warren, D. and Thomas, J.P. (2002) Phase II trial of perillyl alcohol in patients with metastatic colorectal cancer. Int. J. Gastrointest. Cancer, 32, 125-128.

69. Chen, T.C., Cho, H.Y., Wang, W., Wetzel, S.J., Singh, A., Nguyen, J., Hofman, F.M. and Schönthal, A.H. (2015) Chemotherapeutic effect of a novel temozolomide analog on nasopharyngeal carcinoma in vitro and in vivo. J. Biomed. Sci., 22, 71.

70. Bardon, S., Foussard, V., Fournel, S. and Loubat, A. (2002) Monoterpenes inhibit proliferation of human colon cancer cells by modulating cell cycle-related protein expression. Cancer Lett., 181, 187-194.

71. Yeruva, L., Pierre, K.J., Elegbede, A., Wang, R.C. and Carper, S.W. (2007) Perillyl alcohol and perillic acid induced cell cycle arrest and apoptosis in non small cell lung cancer cells. Cancer Lett., 257, 216-226.

72. Ferraz, R.P., Bomfim, D.S., Carvalho, N.C., Soares, M.B., da Silva, T.B., Machado, W.J., Prata, A.P.N., Costa, E.V., Moraes, V.R.S., Nogueira, P.C.L. and Bezerra, D.P. (2013) Cytotoxic effect of leaf essential oil of Lippia gracilis Schauer (Verbenaceae). Phytomedicine, 20, 615-621.

73. Li, J., Liu, C. and Sato, T. (2016) Novel antitumor invasive actions of $\mathrm{p}$-Cymene by decreasing MMP-9/TIMP-1 expression ratio in human fibrosarcoma HT-1080 cells. Biol. Pharm. Bull., 39, 1247-1253.

74. Saleh, M., Hashem, F. and Glombitza, K. (1998) Cytotoxicity and in vitro effects on human cancer cell lines of volatiles of Apium graveolens var filicinum. Pharm. Pharmacol. Lett., 8, 97-99.

75. Silva, S.L.d., Figueiredo, P.M. and Yano, T. (2007) Cytotoxic evaluation of essential oil from Zanthoxylum rhoifolium Lam. leaves. Acta Amaz., 37, 281-286.
76. Maggi, F., Fortuné Randriana, R., Rasoanaivo, P., Nicoletti, M., Quassinti, L., Bramucci, M., Lupidi, G., Petrelli, D., Vitali, L.A., Papa, F. and Vittori, S. (2013) Chemical composition and in vitro biological activities of the essential oil of Vepris macrophylla (Baker) I. Verd. endemic to Madagascar. Chem. Biodivers., 10, 356-366.

77. Kuo, Y.H., Kuo, Y.J., Yu, A.S., Wu, M.D., Ong, C.W., Kuo, L.M.Y., Huang, J.T., Chen, C.F. and Li, S.Y. (2003) Two novel sesquiterpene lactones, cytotoxic vernolide-A and-B, from Vernonia cinerea. Chem. Pharm. Bull., 51, 425-426.

78. Dahham, S.S., Tabana, Y.M., Iqbal, M.A., Ahamed, M.B., Ezzat, M.O., Majid, A.S. and Majid, A.M. (2015) The anticancer, antioxidant and antimicrobial properties of the sesquiterpene $\beta$-caryophyllene from the essential oil of Aquilaria crassna. Molecules, 20, 11808-11829.

79. Jung, J.I., Kim, E.J., Kwon, G.T., Jung, Y.J., Park, T., Kim, Y., Yu, R., Choi, M.S., Chun, H.S., Kwon, S.H., Her, S., Lee, K.W. and Park, J.H. (2015) $\beta$-Caryophyllene potently inhibits solid tumor growth and lymph node metastasis of B16F10 melanoma cells in high-fat diet-induced obese C57BL/6N mice. Carcinogenesis, 36, 1028-1039.

80. Sarvmeili, N., Jafarian-Dehkordi, A. and Zolfaghari, B. (2016) Cytotoxic effects of Pinus eldarica essential oil and extracts on HeLa and MCF-7 cell lines. Res. Pharm. Sci., 11, 476-483.

81. Legault, J. and Pichette, A. (2007) Potentiating effect of $\beta$ caryophyllene on anticancer activity of $\alpha$-humulene, isocaryophyllene and paclitaxel. J. Pharm. Pharmacol., 59, 1643-1647.

82. Lesgards, J.F., Baldovini, N., Vidal, N. and Pietri, S. (2014) Anticancer activities of essential oils constituents and synergy with conventional therapies: a review. Phytother. Res., 28, 1423-1446.

83. Savelev, S.U., Okello, E.J. and Perry, E.K. (2004) Butyryl-and acetyl-cholinesterase inhibitory activities in essential oils of Salvia species and their constituents. Phytother. Res., 18, 315-324.

84. Liu, Z.B., Niu, W.M., Yang, X.H., Yuan, W. and Wang, W.G. (2010) Study on perfume stimulating olfaction with volatile oil of Acorus gramineus for treatment of the Alzheimer's disease rat. J. Tradit. Chin. Med., 30, 283-287.

85. Majlessi, N., Choopani, S., Kamalinejad, M. and Azizi, Z. (2012) Amelioration of amyloid $\beta$-induced cognitive deficits by Zataria multiflora Boiss. essential oil in a rat model of Alzheimer's disease. CNS Neurosci. Ther., 18, 295-301.

86. Cioanca, O., Hritcu, L., Mihasan, M., Trifan, A. and Hancianu, M. (2014) Inhalation of coriander volatile oil increased anxiolytic-antidepressant-like behaviors and decreased oxidative status in beta-amyloid (1-42) rat model of Alzheimer's disease. Physiol. Behav., 131, 68-74.

87. Oboh, G., Olasehinde, T.A. and Ademosun, A.O. (2014) Essential oil from lemon peels inhibit key enzymes linked to neurodegenerative conditions and pro-oxidant induced lipid peroxidation. J. Oleo Sci., 63, 373-381.

88. Abuhamdah, S., Abuhamdah, R., Howes, M.J., Al-Olimat, S., Ennaceur, A. and Chazot, P.L. (2015) Pharmacological and neuroprotective profile of an essential oil derived from leaves of Aloysia citrodora Palau. J. Pharm. Pharmacol., 67, 13061315.

89. Ayaz, M., Junaid, M., Ullah, F., Sadiq, A., Khan, M.A., Ahmad, W., Shah, M.R., Imran, M. and Ahmad, S. (2015) Comparative chemical profiling, cholinesterase inhibitions 
and anti-radicals properties of essential oils from Polygonum hydropiper L: A Preliminary anti-Alzheimer's study. Lipids Health Dis., 14, 141.

90. Klein-Júnior, L.C., dos Santos Passos, C., Tasso de Souza, T.J., Gobbi de Bitencourt, F., Salton, J., de Loreto Bordignon, S.A. and Henriques, A.T. (2016) The monoamine oxidase inhibitory activity of essential oils obtained from Eryngium species and their chemical composition. Pharm. Biol., 54, 1071-1076.

91. Mühlbauer, R., Lozano, A., Palacio, S., Reinli, A. and Felix, R. (2003) Common herbs, essential oils and monoterpenes potently modulate bone metabolism. Bone, 32, 372-380.

92. Koo, B.S., Lee, S.I., Ha, J.H. and Lee, D.U. (2004) Inhibitory effects of the essential oil from SuHeXiang Wan on the central nervous system after inhalation. Biol. Pharm. Bull., 27, 515-519.

93. Lima, B., López, S., Luna, L., Agüero, M.B., Aragón, L., Tapia, A., Zacchino, S., López, M.L., Zygadlo, J. and Feresin, G.E. (2011) Essential oils of medicinal plants from the central andes of Argentina: chemical composition, and antifungal, antibacterial, and insect-repellent activities. Chem. Biodivers., 8, 924-936.

94. El-Seedi, H.R., Khalil, N.S., Azeem, M., Taher, E.A., Göransson, U., Pålsson, K. and Borg-Karlson, A.K. (2012) Chemical composition and repellency of essential oils from four medicinal plants against Ixodes ricinus nymphs (Acari: Ixodidae). $J$. Med. Entomol., 49, 1067-1075.

95. Mkaddem, M., Bouajila, J., Ennajar, M., Lebrihi, A., Mathieu, F. and Romdhane, M. (2009) Chemical composition and antimicrobial and antioxidant activities of Mentha (longifolia L. and viridis) essential oils. J. Food Sci., 74, M358-M363.

96. Hong, Y.K., Park, S.H., Lee, S., Hwang, S., Lee, M.J., Kim, D., Lee, J.H., Han, S.Y., Kim, S.T., Kim, Y.K., Jeon, S., Koo, B.S. and Cho, K.S. (2011) Neuroprotective effect of SuHeXiang Wan in Drosophila models of Alzheimer's disease. J. Ethnopharmacol., 134, 1028-1032.

97. Park, S.H., Lee, S., Hong, Y.K., Hwang, S., Lee, J.H., Bang, S.M., Kim, Y.K., Koo, B.S., Lee, I.S. and Cho, K.S. (2013) Suppressive effects of SuHeXiang Wan on amyloid- $\beta 42-$ induced extracellular signal-regulated kinase hyperactivation and glial cell proliferation in a transgenic Drosophila model of Alzheimer's disease. Biol. Pharm. Bull., 36, 390-398.

98. Liu, Q.F., Jeong, H., Lee, J.H., Hong, Y.K., Oh, Y., Kim, Y.M., Suh, Y.S., Bang, S., Yun, H.S., Lee, K., Cho, S.M., Lee, S.B., Jeon, S. Chin, Y.W., Koo, B.S. and Cho, K.S. (2016) Coriandrum sativum suppresses A $\beta 42$-induced ROS increases, glial cell proliferation and ERK activation. Am. J. Chin. Med., 44, 1325-1347.
99. Liu, Q.F., Lee, J.H., Kim, Y.M., Lee, S., Hong, Y.K., Hwang, S., Oh, Y., Lee, K., Yun, H.S., Lee, I.S., Jeon, S., Chin, Y.W., Koo, B.S. and Cho, K.S. (2015) In vivo screening of traditional medicinal plants for neuroprotective activity against A $\beta 42$ cytotoxicity by using Drosophila models of Alzheimer's disease. Biol. Pharm. Bull., 38, 1891-1901.

100. Hur, J., Pak, S.C., Koo, B.S. and Jeon, S. (2013) Borneol alleviates oxidative stress via upregulation of $\mathrm{Nrf} 2$ and $\mathrm{Bcl}-2$ in SH-SY5Y cells. Pharm. Biol., 51, 30-35.

101. Tian, L.L., Zhou, Z., Zhang, Q., Sun, Y.N., Li, C.R., Cheng, C., Zhong, Z.Y. and Wang, S.Q. (2007) Protective effect of $( \pm)$ isoborneol against 6-OHDA-induced apoptosis in SHSY5Y cells. Cell. Physiol. Biochem., 20, 1019-1032.

102. Han, M., Liu, Y., Zhang, B., Qiao, J., Lu, W., Zhu, Y., Wang, Y. and Zhao, C. (2011) Salvianic borneol ester reduces $\beta$ amyloid oligomers and prevents cytotoxicity. Pharm. Biol., 49, 1008-1013.

103. Calleja, M.A., Vieites, J.M., Montero-Meterdez, T., Torres, M.I., Faus, M.J., Gil, A. and Suárez, A. (2013) The antioxidant effect of $\beta$-caryophyllene protects rat liver from carbon tetrachloride-induced fibrosis by inhibiting hepatic stellate cell activation. Br. J. Nutr., 109, 394-401.

104. Sharma, C., Al Kaabi, J.M., Nurulain, S.M., Goyal, S.N., Kamal, M.A. and Ojha, S. (2016) Polypharmacological properties and therapeutic potential of $\beta$-caryophyllene: a dietary phytocannabinoid of pharmaceutical promise. Curr. Pharm. Des., 22, 3237-3264.

105. Cheng, Y., Dong, Z. and Liu, S. (2014) $\beta$-Caryophyllene ameliorates the Alzheimer-like phenotype in APP/PS1 mice through CB2 receptor activation and the PPAR $\gamma$ pathway. Pharmacology, 94, 1-12.

106. Porres-Martínez, M., González-Burgos, E., Carretero, M.E. and Gómez-Serranillos, M.P. (2016) In vitro neuroprotective potential of the monoterpenes $\alpha$-pinene and 1,8-cineole against $\mathrm{H} 2 \mathrm{O} 2$-induced oxidative stress in $\mathrm{PC} 12$ cells. $Z$. Naturforsch., C, J. Biosci., 71, 191-199.

107. Sammi, S.R., Trivedi, S., Rath, S.K., Nagar, A., Tandon, S., Kalra, A. and Pandey, R. (2016) 1-Methyl-4-propan-2-ylbenzene from Thymus vulgaris Attenuates Cholinergic Dysfunction. Mol. Neurobiol. [Epub ahead of print].

108. Lee, Y. (2016) Cytotoxicity evaluation of essential oil and its component from zingiber officinale roscoe. Toxicol. Res., 32 , 225-230.

109. Bakkali, F., Averbeck, S., Averbeck, D. and Idaomar, M. (2008) Biological effects of essential oils-a review. Food Chem. Toxicol., 46, 446-475. 